\title{
Issues in Managing Profit Equalization Reserves and Investment Risk Reserves in Islamic Banks
}

\author{
V.Sundararajan ${ }^{1}$
}

\begin{abstract}
The use of investment risk reserve (IRR) is key to covering potential losses on assets invested with investment account holders (IAH) funds, and profit equalization reserve (PER) is needed to smooth the returns, so that a desired return to IAH can be provided in the face of volatility in asset returns, and thereby help manage the level of displaced commercial risk (DCR); but the relationship between PER/IRR and DCR is complex. Certain minimum amounts are needed to ensure that a targeted risk return combination can be provided to the IAH with a high probability, even if on some rare occasions asset return may turn negative, requiring the use of IRR to offsetthe losses, and some PER to ensure a market related return to IAH. Since a variety of combinations of PER and IRR can yield a specific targeted return, the appropriate combination will have to be decided by IIFS management based on the expectations of the likely usage of these reserves in the future.
\end{abstract}

\section{Introduction}

The rapid expansion of Islamic Finance in recent years has highlighted the need for policies to help integrate Islamic finance in the national and global financial systems. In particular, the design and implementation of Basel II equivalent standards for Islamic banks, and the adoption of effective risk management systems for these banks, both reflecting the specific operational features of Islamic finance, have assumed center stage. While Islamic Financial Services Board has issued a range of prudential standards and guidelines that together constitute Basel II equivalent for Islamic finance, the implementation of these standards calls for new risk measurement approaches. In particular, an issue of critical importance in risk management of Institutions Offering Islamic Financial Services (IIFS, or Islamic Banks) globally, is how to measure and manage the risk characteristics of Profit Sharing Investment Accounts (PSIA), the major source of funding of IIFS. PSIA held by Investment Account Holders (IAH) constitute about $62 \%$ of assets on average for a sample of Islamic banks in 12 countries in Middle East and South East Asia, Given this significance of PSIA as a funding source, an effective management of the risk return characteristics of these accounts-referred to as investment account management, defined more rigorously later in the paper-- can be used to control the

\footnotetext{
${ }^{1}$ Director, Centennial Group Holdings LLC, Washington DC, vsrajan@centennial-group.com
} 
risks borne by shareholders and the associated economic capital requirements of Islamic banks. Such investment account management, therefore, serves as a powerful risk mitigant in Islamic finance, a unique feature not available for conventional banks.

In principle, under the Mudharabah contract that typically governs the Profit Sharing Investment Accounts (PSIA), all losses on investments financed by these funds (due to credit and market risks) are to be borne by IAH, while the profits on these investments are shared between the IAH and the IIFS as manager of the investments (Mudharib) in the proportions specified in the contract. However, any loss due to "misconduct and negligence" (operational risk), should be borne by the IIFS, under the Shariah principles applying to Mudharabah contracts. In practice, however, the managements of IIFS may engage in a range of practices( as discussed further below) that cushion the returns paid to IAH, thus protecting, as required, the cash flows from IAH funds against variations in the IIFS's income from assets financed by those funds, in order to pay market-related compensation to IAH. In light of such practices, the measurement and management of the sharing of returns and risks between shareholders and investment account holders, taking into account the risk-return preferences of each, and bearing in mind that IAH will in general be more risk-averse than shareholders, is a fundamental issue in Islamic finance world wide, an issue that has not yet been adequately addressed.

IIFS may set aside, build up, and drawdown two types of reserves-Profit Equalization Reserves(PER), and Investment Risk Reserves (IRR)-in order to smooth the returns actually paid out to the Profit Sharing Investment Accounts (PSIA) owned by Investment Account Holders(IAH). The build up and draw down of these reserves can help cushion the returns paid to IAH and preserve the value of IAH funds against variations in the IIFS's income from assets invested with IAH funds, and thereby help pay market related compensation to IAH. IIFS may maintain the payout to IAH at market related levels even though actual asset returns exceed market benchmark rates, by setting aside Profit Equalization Reserves (PER from the profits before the distribution of shares in those profits to IAH and to the IIFS) and Investment Risk Reserves (IRR from the profits available for distribution to the IAH but after paying the IIFS's share of profits as Mudarib).The part of accumulated PER that serves as the equity of IAH and shareholders can then be drawn down to smooth the payout to IAH and shareholders, when investment returns decline; the accumulated IRR, which belongs entirely to IAH, can be used to cover any losses (negative asset returns) that might arise from time to time. A part of accumulated PER belongs to shareholders, and this can also be drawn down to smooth the payout to IAH and shareholders. In addition, when asset returns are low, and PER is insufficient, IIFS owners may transfer some portion of their income or reserves to $\mathrm{IAH}$, thereby offering returns to IAH that are close to market levels despite insufficient asset returns. Such transfer of resources from IIFS owners to IAH could be achieved by reducing the Mudarib's share below the contracted share, and/or by 
otherwise assigning a lower profit or larger losses to shareholders temporarily in order to benefit the IAH, thereby cushioning the impact on IAH of low asset returns.

The combination of these policies - setting aside and drawing down reserves that serve as equity of IAH, accepting cuts in Mudarib's share, and transferring current income or other shareholder funds to IAH if needed and permissible -- can alter the time profile of IIFS owners' profits, and hence the size of risks (unexpected losses) that they bear compared to the situation where all losses are fully borne by the IAH. Issues in measuring this "displacement" of risk from IAH to IIFS owners-so called "Displaced Commercial Risk" - are among the core concerns of Supervisors. The critical role played by the use of PER and IRR in enabling a smoothing of IAH returns ,and hence ultimately on the level of "displaced commercial risk" calls for appropriate policies to manage PER and IRR and proper criteria for assessing adequacy of PER and IRR. A preliminary analysis of considerations in managing PER/IRR and assessing the adequacy of such reserves is a key objective of this paper.

Thus, in practice, there is considerable ambiguity in the nature and characteristics of PSIA in Islamic Banks. The nature of PSIA could vary among banks and jurisdictions, from being deposit-like products (that carry no risk of loss of principal) in some, to being investment-like products (that bear the risk of losses in the underlying investments) in others. Depending upon the extent of investment risks actually borne by the PSIA, these instruments could, in principle, be positioned anywhere in the continuum from being pure deposits (in the conventional sense) to pure investments. The resulting challenge for IIFS and their regulators is to assess where in the continuum the PSIA in a specific bank in a specific jurisdiction lie, and what this implies for the level of risks for shareholders and hence for the level of regulatory and economic capital requirements for that bank.

The recently issued Islamic Financial Services Board (IFSB) Capital Adequacy Standard recommends that supervisors should assess the extent of risks borne by PSIA, based on management decisions on the payout to IAH, and should reflect these assessments in the computation of capital adequacy. This is referred to as "supervisory discretion formula". More specifically, the IFSB supervisory discretion formula for the capital adequacy ratio (CAR) specifies that a fraction "alpha" of the assets funded by PSIA may be included in the denominator of the CAR, where the permissible value for "alpha" is subject to supervisory discretion. The supervisory assessment of how an IIFS manages the risk-return profile of PSIA would determine "alpha", with "alpha near zero" reflecting a pure investment-like product, and "alpha close to one" capturing a pure deposit-like product.

As argued below, bank policies regarding PER and IRR play a critical role in determining the size of "alpha", and hence the bank's capital adequacy. If PER and IRR are adequate to avoid transfer of income from shareholders to IAH in order to maintain a targeted return to IAH, then there is no displaced commercial risk, and PSIA can be treated as an investment product, with "alpha" equaling zero. If PER 
and IRR are not sufficient to avoid transfer of income from shareholders to IAH, and that some transfer together with the use of PER/IRR is necessary to achieve the targeted returns to IAH, then both DCR and "alpha" are positive. A methodology for the estimation of DCR and "alpha" is developed in Archer, Karim, and Sundararajan (2008). In this paper the focus will be to analyze the relationship between the policies on the size of IRR and PER and the size of DCR, and to highlight the prudential issues raised by these policies. Section 2 briefly mentions the currently used accounting and prudential standards on PER and IRR, and presents some data on actual practices. Section 3 presents an analysis of considerations in deciding on the levels of PER and IRR and their relationship to DCR. Section 4 provides some concluding remarks.

\section{Accounting Definitions, and current practices}

The accounting definitions of these reserves, and how these are linked to asset returns and returns to IAH, are discussed below, based on standards issued by the Accounting and Auditing Organization for Islamic Financial Institutions (AAOIFI).

According to Financial Accounting Standards Number 6 (FAS 6) of the Accounting and Auditing Organization for Islamic Financial Institutions (AAOIFI), when a bank commingles own funds ( $\mathrm{K}=$ Capital) with mudarabah Funds (DI=Unrestricted Investment Deposits), profits are first allocated between mudarib's Funds and the fund's of investment account holders, and then the share of Islamic Bank as a mudarib for its work is deducted from the share of profits allocated to the investment account holders.

In addition, FAS 6 states that profits of an investment jointly financed by the Islamic Bank and unrestricted investment account holders should be allocated between them according to the contribution of each of the two parties in the jointly financed investment. Allocation of profit based on percentages agreed upon by the two parties is also juristically acceptable (for example in Musharakha contracts), but the standards call for proportionate contribution.

The minimum standards for calculating the rate of return - specified by Bank Negara Malaysia in the "Framework of the Rate of Return" (2001, and 2004) calls for the share of profits to depositors (and to the Bank as mudarib) be uniform across banks as specified in the framework documents, and provides a uniform definition of profit and provisions to ensure a level playing field. Profit is defined as income from balance sheet assets plus trading income minus provisions, minus profit equalization reserves, minus the income attributable to capital, specific investments, and due from other institutions. This is the mudarabah income (RM) distributable between investment depositors and bank (as mudarib). Provisions are defined as general provisions plus specific provisions \& income-in-suspense for facilities that are non- 
performing. The framework then distributes mudarabah Income between depositors and bank as mudarib and then by type and structure of deposits. ${ }^{2}$

In addition, both AAOIFI standards and the rate of return Framework of BNM recognize Profit Equalization Reserve and Investment Risk Reserve. Profit Equalization Reserves (PER or Rp) refer to account appropriated out of gross income in order to maintain certain level of return for PSIA; and this is apportioned between investment account holders and shareholders in the same proportions that apply to the sharing of profits. Investment Risk Reserves (IRR or $\mathrm{R}_{\mathrm{IR}}$ ) are reserves attributable entirely to investment account holders, but maintained specifically to absorb periodic losses in whole or in part and also to smooth the rate of return actually paid out over time.

AAOIFI standards - and some national regulations - allow PER and IRR to be treated as Tier II capital. In contrast, IFSB capital adequacy standards allow for deduction of PER and IRR from the risk weighted assets funded by PSIA before applying the relevant capital requirements. The IFSB capital adequacy standard allows a share ("alpha") of risk weighted assets funded by PSIA net of PER/IRR to be included in the denominator, with the share "alpha" subject to supervisory direction and approval.

Publicly available information on IIFS practices on PER and IRR is rather limited. In an analysis of disclosure practices of IIFS (drawing on annual reports of a sample of IIFS for 2001-2003), only about $30 \%$ of the banks surveyed disclosed the amount of PER in their balance sheets (Sundararajan (2005)). Most central banks leave the methodology for the calculation of rate of return on PSIA- including calculation and use of PER and IRR- to be decided by the IIFS at their own discretion, and there are no specific supervisory disclosure requirements on PER/IRR, other than those arising from the applicable accounting standards.

In a recent IFSB survey of 15 central Banks and supervisory authorities on the disclosure regime for their IIFS, only 4 authorities imposed specific guidance on PER/IRR, 6 required the IIFS to disclose policies for forming these reserves and on management limits on such reserves and only 5 authorities required disclosure of actual usage of PER/IRR. Bank Negara Malaysia (2001, 2004), in its guidance to Islamic Banks on the rate of return calculations proposes some limits on the size of PER that can be built up, and on the amount that can be deducted from gross income (i.e., prior to calculating the amount distributable to IAH). There is no guidance or limits on IRR in the BNM Guidance documents.

\footnotetext{
${ }^{2}$ Thus, the income to the bank has two components: the return on bank capital used in calculating the mudarabha profits (this is the return to bank's contribution as a co-investor) plus the share of mudarabha profits (this is the fee for its asset management services).
} 


\section{Determinants of PER/IRR and their relationship to DCR}

For measuring risks facing IAH, and the risk sharing between IAH and IIFS, and to assess the role of PER/IRR in determining these risk characteristics, a basic framework for calculating Mudaraba Profit (RM) needs to be specified. RM can be written as

$$
\mathrm{RM}=\mathrm{A}\left(\mathrm{R}_{\mathrm{A}}-\mathrm{Sp}\right)-\mathrm{AR}_{\mathrm{P}}-\mathrm{K} \mathrm{R}_{\mathrm{K}}
$$

Where $\mathrm{R}_{\mathrm{A}}=$ return on assets, $\mathrm{R}_{\mathrm{p}}=$ Profit Equalization Reserves (as a \% assets)

$$
\begin{aligned}
& \mathrm{S}_{\mathrm{p}}=\text { Provisions as a \% of assets, } \\
& \mathrm{R}_{\mathrm{K}}=\left(\mathrm{R}_{\mathrm{A}}-\mathrm{S}_{\mathrm{P}}\right)-\mathrm{D}_{\mathrm{K}}
\end{aligned}
$$

where $D_{K}$ is any transfer of resources from IIFS owners to IAH expressed as a percentage of capital. Thus, when $\mathrm{D}_{\mathrm{K}}$ is zero, the shareholders receive a share of the total asset return in proportion to their contribution to the commingled pool. If $\mathrm{D}_{\mathrm{K}}>$ 0 , shareholders have transferred some resources to IAH in order to provide a targeted return to IAH (see below for further discussion), in the process reducing shareholder returns.

$$
\mathrm{A}=\mathrm{K}+\mathrm{DI} \text {. }
$$

That is, total assets (A) equal the sum of share holder funds (K), and PSIA funds (DI).

Rate of Return for Investment Account holders $\left(\mathrm{R}_{\mathrm{I}}\right)$ can then be calculated by applying the agreed share $\beta$ on Mudarabah profit, and subtracting Investment Risk Reserves $\left(R_{I R}\right.$,expressed as a percentage of IAH deposits)

$$
\mathrm{R}_{\mathrm{I}}=\beta \mathrm{RM} / \mathrm{DI}-\mathrm{R}_{\mathrm{IR}}=\beta\left[\mathrm{A}\left(\mathrm{R}_{\mathrm{A}}-\mathrm{S}_{\mathrm{p}}-\mathrm{R}_{\mathrm{P}}\right)-\mathrm{K} \mathrm{R}_{\mathrm{K}}\right] / \mathrm{DI}-\mathrm{R}_{\mathrm{I}}
$$

In practice, there are two ways to categorize how $\mathrm{R}_{\mathrm{K}}$ is determined. One approach, practiced in many jurisdictions, (for example, see the Rate of Return Framework provided by Bank Negara Malaysia), is to treat $R_{K}$ as an endogenous decision variable that is determined by management. For example, the Bank management may choose $D_{K}>0$, --and hence the overall return to shareholder funds -such that the IAH receive a targeted return that is commensurate with their risk bearing capacity (see below for further clarification of this idea). An alternative approach is to assume that the return to capital in the commingled pool is proportional to its contribution to the pool, and hence the investment return to capital is the same as the return $\left(\mathrm{R}_{\mathrm{A}}-\mathrm{S}_{\mathrm{P}}\right)$ obtained from assets funded by the commingled funds. The variable " $\mathrm{D}_{\mathrm{K}}$ " thus serves as a "donation" from a shareholder from time to time that is determined to ensure that risk-return expectations of IAH are met.

First, assuming $R_{K}$ is endogenous, the return to equity can be written as the sum of investment income earned by shareholders from the commingled funds $\left(\mathrm{KR}_{\mathrm{K}}\right.$ ), income earned as Mudarib ( (1- $\beta) \mathrm{RM}$, where (1- $\beta)$ is the Mudarib's share), and the 
share of PER accruing to the shareholders $\left((1-\beta) . A . R_{P}\right)$, all expressed as a proportion of total capital.; other sources of shareholder income, for example from other banking services and other non-PSIA assets, are ignored for simplicity. The return on equity, as defined above, is shown in equation (3) below.

$$
\mathrm{R}_{\mathrm{E}}=(1-\beta)\left\{\mathrm{RM} / \mathrm{K}+\mathrm{A} \mathrm{R}_{\mathrm{P}} / \mathrm{K}\right\}+\mathrm{R}_{\mathrm{K}}
$$

Combining equations (1), (2) and (3), and simplifying the expressions, yields:

$$
\begin{aligned}
& \mathrm{R}_{\mathrm{I}}=\beta\left(\mathrm{R}_{\mathrm{A}}-\mathrm{Sp}\right)-\beta \mathrm{A} / \mathrm{DI} . \mathrm{R}_{\mathrm{P}}+\mathrm{K} / \mathrm{DI} \cdot \beta \cdot \mathrm{D}_{\mathrm{K}}-\mathrm{R}_{\mathrm{IR}} \\
& \left.\mathrm{R}_{\mathrm{E}}=(1+(1-\beta) \mathrm{DI} / \mathrm{K})\right) \cdot\left(\mathrm{R}_{\mathrm{A}^{-}} \mathrm{S}_{\mathrm{P}}\right) \cdot-\beta \mathrm{D}_{\mathrm{K}}
\end{aligned}
$$

Investment risk facing IAH and shareholders can be computed based on the variance of $R_{I}$ and $R_{E}$, respectively. For example,

$$
\begin{gathered}
\operatorname{VAR}\left(\mathrm{R}_{\mathrm{E}}\right)=\{1+(1-\beta) \mathrm{DI} / \mathrm{K}\}^{2} \operatorname{VAR}\left(\mathrm{R}_{\mathrm{A}}-\mathrm{S}_{\mathrm{P}}\right)+\beta^{2} \operatorname{VAR}\left(\mathrm{D}_{\mathrm{K}}\right)-2 \beta\{1+(1- \\
\beta) \mathrm{DI} / \mathrm{K}\} \operatorname{COV}\left(\left(\mathrm{R}_{\mathrm{A}}-\mathrm{S}_{\mathrm{P}}\right), \mathrm{D}_{\mathrm{K}}\right)
\end{gathered}
$$

Similarly, the investment risk to IAH can be computed by calculating the variance of $\mathrm{R}_{\mathrm{I}}$ and its components based on equation (5).

Thus, true risk facing shareholders- which is the main determinant of the CAR - is given by equation (6). This risk to shareholders is determined primarily by three components: 1).the variability of investment returns; 2).variability of the income transfers from shareholders to IAH; and3).the covariance between investment returns and the income transfers. The larger is the asset return, the less is the need for income transfer from shareholders, and hence this covariance is expected to be negative. The larger is this covariance, in absolute terms, the larger is the risk to shareholders and hence the larger is the capital requirements. In addition, IIFS may adjust the Mudarib's share $1-\beta$ as an additional mechanism for income smoothing. Under Mudarabah contract, the investment losses on PSIA funds are to be borne by IAH, and hence Mudarib's share, (1- $\beta$ ), cannot fall below zero in case of losses (that is, $\beta=1$, whenever $\left.\left(\mathrm{R}_{\mathrm{A}}-\mathrm{S}_{\mathrm{P}}\right)<0\right)$. Similarly, in case of losses, shareholders cannot make up for negative returns by transfers from shareholder funds (that is, $D_{K}=0$, if $\left(\mathrm{R}_{\mathrm{A}}-\mathrm{S}_{\mathrm{P}}\right)<0$ ). In view of these constraints on the behavior of $\mathrm{D}_{\mathrm{K}}$ and $\beta$, it is assumed that sufficient amount of accumulated PER and IRR is available to achieve the targeted return to IAH even when asset returns are negative.

A key implication of equation (6) is that the risk facing shareholders -and hence the capital requirements -- is independent of PER and IRR, if $D_{K}=0$, and $\beta$ is fixed. That is, if an IIFS can manage the value and returns on Investment accounts entirely though adjustments in PER and IRR, without recourse to any income transfer from shareholders, then the displaced commercial risk is zero, and there is no need to hold additional capital requirements for such risk, and hence "alpha" is zero. This observation raises the following questions. What is the desired or adequate level of $\mathrm{PER} / \mathrm{IRR}$, the use of which will ensure that there is no displaced commercial risk 
(DCR $=0$, or "alpha" in the IFSB supervisory discretion formula is zero) and hence PSIA can be treated as pure investment product requiring no additional capital requirements on IIFS (other than for operational risk)? Alternatively, given a specific policy of IIFS relating to DCR, what should be the desired level of PER/IRR that will help support that policy? In the extreme, if DCR is at its maximum possible value, with alpha equal to one, then PSIA is similar to deposits, and then what should be the adequate level of PER/IRR that would ensure that IAH returns behave like bank deposit returns

In order to address these questions, the relationship between usage of PER/IRR and the policy on returns to IAH that determines the extent of DCR should be analyzed. This relationship can be highlighted by rewriting equation (4):

$$
R_{I R}+\frac{\beta\left(R_{P}\right)}{\beta^{\prime}}-\frac{\beta\left(1-\beta^{\prime}\right)}{\beta^{\prime}} D_{K}=\beta\left(R_{A}-S_{P}\right)-R_{I}
$$

where $\beta^{\prime}=\mathrm{DI} / \mathrm{A}$. The right hand side of equation (7) can be interpreted as the excess of unsmoothed return to IAH (asset return multiplied by profit share of IAH) over actual payout to IAH. Left hand side is the sum of IRR plus a proportion $\beta$ of PER minus the $\beta$ of transfers from shareholders, all expressed as percentage of PSIA deposits (i.e. DI). Assuming for simplicity, $D_{k}=0$, we get:

$$
R_{I R}+\frac{\beta\left(R_{P}\right)}{\beta^{\prime}}=\beta\left(R_{A}-S_{P}\right)-R_{I}
$$

Equation (8) states that for each value of excess asset return, there is a range of combinations of $R_{I R}$ and $R_{p}$ that would allow the desired payout to IAH for a given realization of asset return. This is illustrated in Figure 1.

Figure 1: Feasible Combinations of PER and IRR, when $R_{A}-S_{P}>0$ (as a \% of DI)

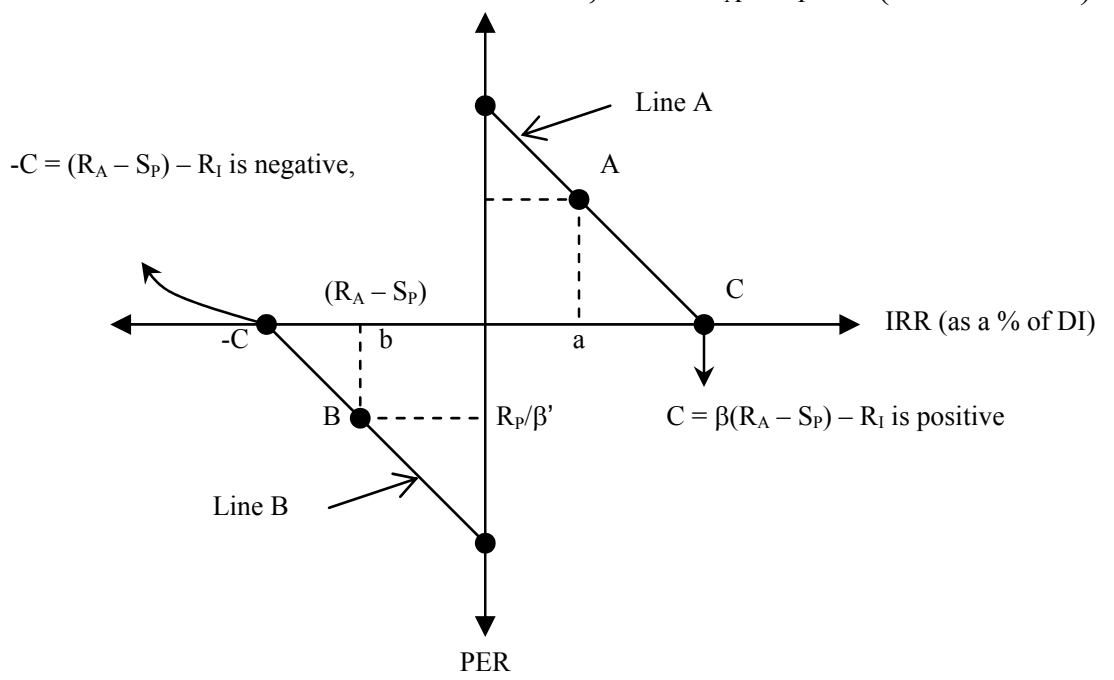


The slope of line $A$ is $1 / \beta$ and various combinations of building up PER and IRR are consistent with the asset return and the payout to IAH. For $R_{A}-S_{P}>0, \beta$ fixed, a specific combination of IRR and PER buildup will be chosen depending upon initial level of PER and IRR, in relation to their derived levels; in principle, any combination of PER/IRR on the line A seems feasible. The chosen combination such as point $\mathrm{A}$ is a decision by IIFS management and Board.

In the case of $\mathrm{R}_{\mathrm{A}^{-}} \mathrm{S}_{\mathrm{p}}<0$, the Mudarabah contract requires that all losses be borne by IAH; hence PER can not be used to cover losses under the typical Mudarabah, and " $1-\beta$ " has to be set at zero, but only the IRR set aside from previously distributable returns to IAH can be so used. It is also possible that IRR is used to bring the IAH return to zero and then calculate appropriate drawdown of PER, (or income transfer $\mathrm{D}_{\mathrm{K}}$ ), that would yield a desired IAH return under these constraints. The feasible combinations of IRR and PER drawdowns are shown in line A, with slope equal to one (as $\beta=1$ ).

The minimum required level of IRR can be defined as the level that will be sufficient to cover the asset losses $\left(\mathrm{R}_{\mathrm{A}}-\mathrm{S}_{\mathrm{P}}\right)$ that will not be exceeded with some probability, such as $99 \%$. This level will ensure that $99 \%$ of the time, there will be enough IRR to bring the IAH return to zero. PER can then be drawn down to provide a positive IAH return. It is assumed in Figure 1 , that asset losses $\left(\mathrm{R}_{\mathrm{A}}-\mathrm{S}_{\mathrm{P}}\right)$ will exceed " $b$ " only about $1 \%$ of the time. Thus point " $b$ " indicates the minimum required level of IRR. A feasible combination of IRR and PER in case of $R_{A}-S_{P}<0$ is thus given by point ' $\mathrm{B}$ ' on line $\mathrm{B}$. Adequate level of PER is one which would allow $\left(R_{P} / \beta^{\prime}\right)$ to equal or exceed $R_{I}, 99 \%$ of the time. Thus adequate level of PER depends on the volatility of $R_{I}$ and hence is not independent of DCR. If DCR $=1$, and $R_{I}=R_{m}$, the minimum required value of PER is determined by the volatility of market benchmark returns.

If, the level of PER and IRR exceeds the minimum requirements and is very large, then any policy on DCR and IAH returns is feasible. In this case size of DCR is indeterminate, but this outcome implies that a large portion of IAH income have not been distributed and were built up when asset returns were above market bench marks and have not yet been distributed, resulting in IAH returns below asset returns for the current holders of investment accounts. Insofar as these reserves are distributed to IAH in the future, this could be at the expense of current IAH, 
reflecting a transfer from current IAH to future IAH. Moreover, the amount of PER /IRR belonging to the IAH can be deducted from the RWA funded by PSIA before applying the share "alpha" and computing the denominator in the supervisory discretion formula. Thus, level of PER/IRR affects IIFS capital adequacy both by influencing "alpha" and by offsetting the base on which "alpha" is applied. This is a situation where, Shareholders benefit at the expense of IAH due to excess build up of PER and IRR. These considerations warrant placing some limits on the size of PER and IRR both on prudential and investor protection grounds.

The above considerations are summarized in tabular form in Figure 2.

Figure 2: Relationship Between PER/IRR and DCR

\begin{tabular}{|c|c|c|}
\hline Size of DCR & $\begin{array}{l}\text { Size of } \\
\text { “alpha” }\end{array}$ & $\begin{array}{l}\text { Adequate level of } \\
\text { PER/IRR }\end{array}$ \\
\hline 0 & 0 & $\mathrm{PER}=0, \mathrm{IRR}=0$ \\
\hline $\begin{array}{c}\text { Maximum } \\
\text { Possible } \\
\text { Level }=\mathrm{DCR}_{1}\end{array}$ & 1 & $\begin{array}{l}\text { Minimum required IRR is } \\
\text { proportional standard } \\
\text { deviation of }\left(\mathrm{R}_{\mathrm{A}}-\mathrm{S}_{\mathrm{P}}\right) \text {. } \\
\text { Minimum required PER is } \\
\text { proportional to standard } \\
\text { deviation of market } \\
\text { benchmark return } \mathrm{R}_{\mathrm{m}} \text {. }\end{array}$ \\
\hline $0<\mathrm{DCR}<\mathrm{DCR}_{1}$ & $\alpha=\frac{D C R}{D C R_{1}}$ & $\begin{array}{l}\text { Minimum required IRR is the } \\
\text { same as above. } \\
\text { Minimum required PER is } \\
\text { proportional to standard } \\
\text { deviation of actual IAH } \\
\text { returns } \mathrm{R}_{\mathrm{I}} \text {. }\end{array}$ \\
\hline $\begin{array}{l}\text { DCR is indeterminate; Any value of DCR } \\
\text { chosen by management is achievable. }\end{array}$ & $\begin{array}{c}\alpha \text { is } \\
\text { indeterminate }\end{array}$ & $\begin{array}{l}\text { Very large build up of PER } \\
\text { and IRR }\end{array}$ \\
\hline
\end{tabular}

Note: The expression for " $\alpha$ " in Figure 2 above is derived in Archer et al (2008). 


\section{Concluding Remarks}

Analysis above shows that the use of IRR is key to covering potential losses on assets invested with IAH funds, and PER is needed to smooth the returns, so that a desired return to IAH can be provided in the face of volatility in asset returns, and thereby help manage the level of DCR; but the relationship between PER/IRR and DCR is complex. Certain minimum amounts are needed to ensure that a targeted risk return combination can be provided to the IAH with a high probability, even if on some rare occasions asset return may turn negative, requiring the use of IRR to offset the losses, and some PER to ensure a market related return to IAH. Since a variety of combinations of PER and IRR can yield a specific targeted return, the appropriate combination will have to be decided by IIFS management based on the expectations of the likely usage of these reserves in the future. It would, however, seem prudent to use transfers to PER and IRR and transfers from shareholders $\left(\mathrm{D}_{\mathrm{k}}\right.$ ) actively in good times to build up rapidly both PER/IRR to adequate levels. It would also be important to establish prudential limits on the size of PER and IRR so as to ensure an appropriate sharing of risks and returns between shareholders and IAH. The development of precise guidance on these issues would require additional empirical work on bank policies on PER/IRR and DCR. 


\section{References}

Simon Archer, Rifaat Ahmed Abdel Karim, and V.Sundararajan, "Are Profit Sharing Investment Accounts (PSIA) Deposits or Investments? Supervisory and Capital Adequacy Implications of PSIA in Islamic Finance", A Study prepared for the Islamic Financial Services Board (IFSB) 2008.

V. Sundararajan, "Risk Measurement, and Disclosure in Islamic Finance and the Implications of Profit Sharing Investment Accounts," paper presented at the Sixth International Conference on Islamic Economics, Banking and Finance, November 22-24, 2005, Jakarta, Indonesia.

Accounting and Auditing Organization for Islamic Financial Institutions (2001), Financial Accounting Standards 6, Equity of Investment Account Holders and Their Equivalent, AAOIFI, Manama, Bahrain.

Bank Negara Malaysia (2001), "The Framework of the Rate of Return," Bank Negara Malaysia, Kuala Lumpur, October 16.

Bank Negara Malaysia (2003), "Guidelines on the Specimen Reports and Financial Statements for Licensed Islamic Banks" (GP8-I), Bank Negara Malaysia, Kuala Lumpur, August.

Central Bank of Bahrain, July 2006, CBB Rule Book for Islamic Banks, Public Disclosure Requirements, Volume 2, Part A, Manama, Bahrain. 